\title{
Adult Learners in an Online College Class: Combining Efficiency and Convenience of E-learning
}

\author{
Peter Serdyukov and Nataliya Serdyukova \\ National University \\ 11255 North Torrey Pines Rd., La Jolla, CA 92037 USA \\ pserdyuk@nu.edu;nserdyuk@nu.edu
}

\begin{abstract}
In view of the growing adult learner population in the USA, the traditional campus-based paradigm of higher education has been shifting towards more efficient innovative models that meet the needs of working adults. These particular needs include practical goals, increased motivation, high demands for quality, structure and organization of the learning process, limited time for study, flexibility and convenience, which imposes certain conditions on the instructional process. Among the many innovative approaches to adult higher education online learning seems to be attracting the most attention among both adult students and educational researchers. This calls for the discussion of instructional approaches and special pedagogy focused on adult learner.
\end{abstract}

\section{Introduction}

According to NCES (2002), adults comprise $39 \%$ of all undergraduate students in the United States. The percent of adults in graduate and post-graduate programs is, by definition, much higher.

There is a significant difference between educational systems oriented at adult ( 25 years and older) and young (18-24 years old) college students [1[2]. Adult pedagogy is built on an andragogical assumption that adults are self-directed learners who are shaped by the accumulation of authentic personal experience. Their desire to learn grows out of a need to confront an ever-changing reality. Adults are not captive learners in the same way as kindergarten through high school students. "Adults vote with their feet," may be cliché, but it indicates that if a learning model does not suit the particular needs of the adult learner, he or she may well exit the school.

Recall Knowles' six assumptions about the adult learner [3]:

- Adults learners are likely to be self-directed

- Adult's life experiences can serve as a unique learning resource.

- Adults are usually goal-oriented learners, not curriculum oriented learners.

- Adults are more likely to initiate and sustain learning due to genuine motivation rather that external incentive. 
- Adults demand an explicit initial framework of study, and then the freedom to pursue knowledge within those borders.

- Adults hate to waste time.

Hence, adult learning is commonly affected by the following factors:

1. Time-efficiency of the learning programs

2. Independence in learning based on life and professional experience and background

3. High intrinsic motivation and responsibility

4. Need for rational structure and organization of the learning process

5. Pragmatism in the choice of the content, methodology and applications, i.e., what and how to study, and what for.

In short, adult learning should be learner-centered, practical and efficient. This calls for the discussion of the pedagogy of online adult learning.

\section{Convenience of learning}

Moreover, our research [4] demonstrates that one of the most important factors in adult learning is convenience. A more recent study of adult learning [5] helped to identify five groups of convenience factors: external, personal, programmatic, procedural and technical ones:

External factors:

- Easy, unobstructed access to learning

- Reduction or elimination (wherever possible) of the commuting, classroom presence, inefficient enrollment, advising and supporting activities

- Cost-efficiency

Personal factors

- Appreciation of the student's opinion and work in the class

- Low anxiety class environment and respectful relationships in the group

- Personal, informal engagement, communication and collaboration with the instructor and the peers

Programmatic factors

- Wide choice of learning programs and formats

- Simplicity of the course structure and its navigation

- Clarity of the goals, outcomes, requirements, content, assignments and evaluation instruments and criteria

- Attainability of the goals, requirements and outcomes

- Short-term, accelerated pace of learning

- Sequential structure of the program (one course at a time - Greiner et al. 2005)

Procedural factors

- Flexibility of the class schedule

- Efficient course delivery

- Smoothness (seamlessness) of the learning process

- Efficiency of the structure, organization and implementation of the instruction 
- Rich, well-organized, multimodal content presentation and learning environments

- Satisfying learning experiences

- Opportunity for using one's background and professional experiences

- Unlimited opportunities for communicating with the peers and the instructor

- Reasonable, measured independent work

- Constructive and expeditious instructor's feedback

- Objective and unambiguous assessment and evaluation

- Customization (individualization) of the learning and of the instructor's interaction with the student

Technical factors

- User-friendly interface

- Technical proficiency of the learner as well as the instructor

When surveyed on the reason for choosing a non-traditional, accelerated model of adult higher education provided by National University, students gave the following responses:

- Short (one-month long), accelerated courses - 71.8\%

- Flexible time of study $-57.1 \%$

- One-course-at-a-time format of the instructional process - $56.0 \%$

Convenience of learning comes as a result of rational planning and organization, effective teaching methodology and educational technology applications, instructor's enthusiasm and professionalism, program delivery adaptation and adequate instructional support. Convenience is essential for student's comfort zone that is a necessary condition for optimal productivity in learning. It becomes one of the major criteria for the adult learner's selecting a college program and remaining in it to the end.

\section{The roots of teaching and learning online}

Although online education is a technological innovation that is a relatively new idea, collaborative learning or more particularly an andragogical approach to learning is built on solid pedagogical notions that extend back at least three centuries. The philosophical roots of a shared approach, which embraces what Malcolm Knowles has defined as self-directed lifelong learning, stem back to the $18^{\text {th }}$ Century, to Jean Jacques Rousseau (1712-78), shaped $19^{\text {th }}$ Century Romanticism by influencing among others Immanuel Kant, Johann Wolfgang von Goethe, and Leo Tolstoy. The $20^{\text {th }}$ Century introduced John Dewey's democratic pragmatism, Jean Piaget's developmental theory and Lev Vygotsky's social constructivism leading toward a path to collaborative interaction in learning.

Online education is a transactional model (as opposed to transmission or banking) that can be with the proper curricular model transformative in nature. This model stems from establishing a learning environment where students choose both interactive (e.g. discussion boards) and autonomous (e.g. essays based on their explicit connections to the readings and authentic personal experience) activities to produce interactions both scholarly and relevant. Among these interactions are learning experiences gained through: the texts and images presented in an online 
course, the instructor to learner and learner with learner collaborations, and a growing sense of empowerment by the learner based on his or her genuine motivation nurtured through a collaborative power sharing format [6]. Students' life experiences and field-based studies in the course also contribute to the collaboration and knowledge construction. This interactive environment is further enhanced in cyberspace. In asynchronous online environment students have the benefit of time and the resources of the World Wide Web in order to have the opportunity to make their responses to a professor's question or assignment on point, scholarly, and based on reflective thought [7].

Online learning can provide learning outcomes that are comparable or even superior to those of conventional educational formats [8]. However, assuring proper skill development in some online courses may be more difficult due to the textual rather than verbal, and distance instead of face-to-face interactions with instructors and peers, as well as the mostly individual nature of such learning.

\section{Andragogy integrated into online education}

Given their goal-oriented approach to learning and an ever more crowded personal calendar (adults hate to waste time!), a self-paced asynchronous online course design has proven to be a most effective instructional approach.

Online learning is conducted via the Internet, usually by educational institutions whose students who are separated from them by distance and time. In some aspects, this approach resembles traditional education, particularly as regards the course goals, objectives, syllabus, content, and learning outcomes, for these must be congruent for both on site and online formats. Also, instructors play a key role, though the instruction in an online environment is mediated through technology. Much more so than onsite versions, online learning is essentially organized and structured self-education. The institution provides the course; the instructor facilitates learning by offering guidance and feedback; but students themselves choose the schedule of study, allocate time, and use their own learning procedures and resources. So, formal online education can be described as an instructorfacilitated learning environment, but for a learner it is, in reality, essentially selfsufficient learning. Hence, the challenges of independent planning, management and self-control arise [9].

Nevertheless, online courses can be effectively self-managed by the student if he or she is supported by the proper instructional tools [10]. It has been noted, however, that online students often do not have efficient learning and selfmanagement skills, which calls for their special development in an online program. Moreover, due to job and family obligations, many working adult students have very busy schedules. Thus, overcoming the challenges of distance learning and helping students learn how to learn in a virtual environment have become two major issues of online education.

The goals and curriculum of an online course should be the same as in the traditional onsite course. The difference between the course given online as opposed to one taking place in a classroom, is in a distinct methodological approach. Accordingly, there is a need to articulate a particular educational philosophy (i.e. 
andragogy - learner-centered adult education) when preparing an online professor or in orienting an online student. It is critical to point out that the training of a professor to teach an online course should be done by a qualified faculty rather than a computer savvy technician. Online pedagogy should be taught by a pedagogue.

An appropriate philosophy informs a coherent methodological approach so that a professor will be prepared for distinctive techniques and the online student will be assured that he or she will receive the most enriched learning experience in an online format. Similarly, an important relationship exists between adult development and online education based on the andragogical notion that adults are self-directed learners. Specifically, adults possess authentic life-long experiences, and have the desire to gain increased knowledge to face the tasks they encounter in their studies and in life. An online course, which asks students to use their critical thinking skills (analysis, synthesis and evaluation) by means of reflective written work, is on solid pedagogical ground. For example, essays which request explicit connections to required readings (new knowledge) as well as the revelation of authentic personal experience (stored knowledge) can lead to enhanced learning. Rigorous academic writing demands higher order critical thinking skills that demand adults confront their ambiguities about issues in educational theory or best practice.

Online classes at the collegiate level can be developed and put into practice as tutorial, group, or independent instructional modes. Given a background of understanding the stages and transitions of adult life, as well as paying special attention to the interrelationship of adult and career development, certain kinds of instructional techniques are indicated. For instance, online approaches that include contract learning, discussion boards, experimental learning, portfolios, choice of assignments and self-pacing in an asynchronous environment seem most fitting. For a growing number of adult learners a powerful new model exists in cyberspace where andragogy affects online course design.

Thus, the logical extension of these assumptions for an online class is a collaborative asynchronous learning format. Such a learner-centered format calls for both direction and support. The key factors in providing a foundation for a partnership among facilitators and learners is to provide both direction and support for all. It is usually up to the facilitator to determine direction (i.e. how to carry out the learning process) and support (the learner's competence to take part in that process) although students familiar with this paradigm can also partake in a shared decision making process. Support for the online adult learner is provided through a learning environment that meets both the adults' affective and cognitive needs. An academic atmosphere in which all have a sense of well-being is an essential element in a collaborative partnership among facilitators and students. Facilitators need to balance between being friendly and challenging the adult learner [11].

\section{Online collaborative learning}

Research indicates that one of the most commonly mentioned characteristics of adult education is its collaborative aspect [12]. Clearly, the foundations of modern adult education have emerged out of the progressive education movement [13]. Yet given this well-known conceptual framework of participation through collaboration, there has been a dearth of empirical evidence to support adult collaborative learning 
especially as it relates to an andragogical model. The data from the online education research presented in this paper indicate that the process of collaborative learning can be a positive methodological approach with adult learners.

Collaborative learning works through the online experience in five distinct ways especially by means of asynchronous discussion boards:

- Both facilitators and learners become participants in an educational process that is both active and reflective.

- The hierarchy among the facilitators and learners is modified (common inquiry is stressed among all adult learners)

- A cyberspace community is created based on scholastic interactions with immediate feedback (e.g. within a 24-hour period).

- A synergy made up of responses, with explicit connections back to readings and lectures along with authentic personal experiences produces a learning model where knowledge is both created and transferred.

- The locus of control shifts from the individual to the participating online community.

The philosophical foundations for this kind of student-centered learning go back to Dewey, Piaget, and Vygotsky. Though all wrote and lived before the invention on online education, their notion that collaborative learning assumes that knowledge is socially, as opposed to individually, constructed by a community of learners is key. When learners shape and test ideas, and authority is distributed and experienced among all in the learning community, that particular process is inherently participatory and therefore collaborative. Collaborative learning differs from autonomous learning in that the course designer fashions a curriculum with appropriate rigor and with a power sharing emphasis so that learning is collegial. The learner is presented with options and alternatives, real choices on how to respond to various developmental tasks within a specific curricular conceptual framework. The role of the facilitator determines the extent of a collaborative learning environment by shifting authority and commensurate responsibility for learning to the student. Thus the facilitator does not perform the traditional role of the sole authority and transmitter of knowledge. Instead, a process of mutual inquiry, where students are viewed as co-learners, is implemented. For the online class a redefinition of control, power, expertise, and authority may well be indicated. It has been stated that "Learning is part of a circuit that is one of life's fundamental pleasures: the [professor's] role is to keep the current flowing" [11]. Online instructors who interact with adults as partners can create, especially in an asynchronous environment, a unique synergy based on reflective thought converted into insightful writing.

Modeling scholarly dialog on the part of the professor in a timely way was a key element. Therefore, what is called for is a judicious mix of the facilitator's sense of responsibility to cover the required course concepts while at the same time being unconditionally committed to enable students to learn on their own and share their new knowledge via discussion boards with the online community. In order to attain that goal a facilitator prepares learners for collaborative work by clear explanations of the particular shared process involved. An example of this can be found in an online course information section. Such a section explains the what (i.e. the 
curriculum) and the how (i.e. the methodological approach) of a course in cyberspace and thus permits students to succeed in a collaborative learning situation. An explicit rationale (e.g. course description, goals, and learning outcomes) and a coherent framework (e.g. assignments, scoring scales, evaluation factors) are essential components of a course information section. Such care in designing an intuitive website has very real implications in terms of student success. After the facilitator has decided the appropriate learning activities, established clear objectives, used suitable participatory techniques, developed meaningful questions, provided a clear sense of expected outcomes, and by means of generic online technology creates an interactive site in cyberspace, an online collaborative learning situation has been formulated.

This formulated environment provides an atmosphere where participants feel at liberty to exchange ideas and share notions in order to create community-based knowledge. The result is a democratic setting where student have a sense of wellbeing and acceptance where the seemingly dichotomous needs of affiliation and autonomy are mutually fulfilled through the commitment to both individual growth and group development inherent to online collaborative education. When a culture of online collaborative learning is constructed with the learner in mind, well-defined shifts in learning take place. Cognitive psychologists have noted that how we learn affects what we learn. Put simply, curricular technology does affect instructional methodology. In this environment, the focus of the education paradigm will shift from teaching to learning.

Traditional Model

- Listener, observer, note taker

- Competition with others

- Attendance at a certain time and place

- Learning independently

- Authority through instructors and texts

- Control and pacing set by instructor and explained to students

\section{Online Collaborative Model}

- Problem-solver, constant contributor

- Collaboration with others

- Choice of a convenient place and time

- Learning interdependently

- Authority shared among facilitators, peers, online "worldwide" and library resources

- Control and flexibility of pacing set by students

One benefit of the online collaborative format is that it provides for an increase of democratic decision making. Correspondingly, the participants can acquire insights to their own academic and social development as well as the potential of group generated knowledge. By making explicit connections back to the texts and using authentic personal experiences, learners are able to expose and resolve previously unshared biases and well as share their collective knowledge and wisdom. This appears to parallel the findings at the primary and secondary level [14], which strongly indicate that learning is enhanced when students experience collaborative group work in a noncompetitive environment.

If we view the adult learner in cyberspace as a mutual partner in the learning process, what is called for is a coherent strategy to serve this particular student population. 


\section{Threaded Discussion as a Primary Tool for Knowledge Construction}

Threaded Discussion (TD) is a tool that has a primary importance for online education: it makes students interact with their peers and with the instructor on relevant topics, and also with the course materials. As opposed to chats, the asynchronous TD format has been shown to provide more consistent opportunities for participation, for revisiting previous postings, deeper levels of student reflection, access to a broader spectrum of ideas, more concrete connections to lecture and readings, and more ways for instructors to model higher order responses, monitor learning, and offer clarification [8].

Asynchronicity of TD allows students time to prepare, reflect, and express themselves in the relatively stress-free environment of their own individual workplace and at their convenience. Using an extended timeframe of TD, students are better able to use and apply the recommended literature and other course resources, search for additional support materials, include quotations, and write their text using appropriate format and style. Thus, TD, in addition to its main role of knowledge construction and collaboration, allows for further development of writing, composition, structuring and formatting skills. Moreover, asynchronous environments tend to reduce anxiety. Synchronous discussions, on the contrary, encourage reaction and spontaneity, but may sacrifice depth of cognition and use of the professional literature. Nevertheless, chat can serve as a complementary tool to the asynchronous TD when used for such purposes as exchange of opinions or ideas on some topic, or for brainstorming, problem solving, or additional clarification by the instructor. Together, they can embrace all of the major characteristics of learning and interaction.

TD has a definite advantage over the other online communication tools (email, chat and videoconferencing) with regard to collaboration and knowledge construction for the following characteristics: academic depth, length of posting (There is evidence of a direct relationship between quantitative and qualitative characteristics of students' learning products (in this case, a TD posting) based on the universal law of transformation of quantity into quality. Therefore, the length of a student's posting can be one of the characteristics of the quality of his or her preparation, in addition to other qualitative characteristics.), expressiveness, collaboration, self-management, retention, and use of resources.

Remarkably, students in online classes participating in TD tend to interact among themselves and with the instructor $12.5 \%$ times more often than required, on average, (2,25 postings per discussion vs. 2.0$)$, and post three times more words than required (360 vs. 120) per discussion [9]. Online learning activities, according to National University online faculty survey (2004), provide an adequate means for students to achieve the desired learning outcomes and to demonstrate their level of achievement. Faculty, however, note the need for more guidance on teaching strategies, especially in effective use of TD, which highlights the importance of continuous instructors' professional development 


\section{Providing equal opportunity in cyberspace}

Perhaps one of the most socially dynamic notions about online teacher education is the creation of an equitable learning environment. Many adults (e.g. women, minorities, the less affluent, persons with disabilities, those who live great distances from a campus) do not fully experience or have been totally shut out of traditional teacher education programs. Theoretically, this group may now have the opportunity, by means of online education, to truly connect with educational offerings and become engaged in the scholastic endeavors of a community of learners. Serving all online learners requires the following:

- Facilitators must model acceptance of every adult learner regardless of gender, perceived ability, race, or ethnic background. It has been said that $80 \%$ of all teaching is modeling. Reaching out in cyberspace is an inclusive enterprise that can bypass much of the traditional bias, which continues to exist in the traditional classroom.

- The curriculum (subjects or topics) should reflect the needs of the group being taught. Recall adults come with an array of experiences and lifelong constructed knowledge from a variety of cultural domains. Images and examples should reflect, acknowledge and validate the diversity among adult learners. This is critical in developing partnerships.

- A facilitator is a leader. A great leader doesn't produce followers, but other leaders. Facilitators must be change agents, believing that change and development is possible for all, and that the roles of facilitators and learners are to assist in that process for the collective academic and social development of the online participants.

- Facilitators, who engage adults as partners through the aforementioned direction and support, may well enjoy a fruitful collaborative learning process. To carry out this mission, the facilitator must lead the adult learner to new levels of understanding and action.

Learning has to be convenient, as mentioned above, which can be described as a composite factor providing encouraging and supportive conditions for student's productive and low-stress learning activity

\section{Conclusions}

Just as online education provides an out-of-class option to the traditional education program, which historically has proven exclusionary, a true power sharing collaborative methodological format challenges traditional assumptions about learning which have also proven exclusionary and limiting. Online models, which change the concepts of time (from synchronous to asynchronous) and space (from the traditional classroom to literally anywhere where a computer can hook up to the Internet or using mobile technology) open new outreach opportunities for an ever more diverse student population by offering higher education courses online and further through mobile equipment. With well-designed online curricula based on an andragogical (for the learner-centered adult) and an asynchronous basis (given the idiosyncratic life style of adults), a wider diversity of the adult population will have 
the ability to enter education programs. The reality of online education is rooted in a new technology; the promise of online education is premised on inclusion. Among many factors contributing to the effectiveness of online adult learning are learnercenteredness, self-sufficiency, pragmatic approach to teaching and learning, effective organization of the learning process, time-efficiency, collaboration in an asynchronous format, and convenience.

\section{References}

1. Merriam S and Caffarella R (1991) Learning in Adulthood: A Comprehensive Guide Jossey-Bass San Francisco

2. Ryan M (2004) Professional Development: A Practitioner's Guide to Setting an Environment for Adult Learning Pearson Boston

3. Knowles M (1991) In Adult Education: Evaluation and Achievements in a Developing Field of Study. John M. Peters (ed) Jossey-Bass San Francisco

4. Serdyukov P, Subbotin I, and Serdyukova N (2003) Accessible, Convenient and Efficient Education for Working Adults in a Shorter Time: Is It Possible? In: CAEL Forum and News, Spring 200326 3, 24-28.

5. Serdyukov P and Serdyukova N (2004) Intensive short-term learning: some approaches to contemporary adult education. In: Int. J. Cont. Engineering Education and Lifelong Learning 14 1/2,58-67

6. Ryan M. and Serdyukov P (2003) Online education for Adults: An Andragogic Approach In: EdMedia 2003 World Conference on Educational Multimedia, Hypermedia \& Telecommunications, Honolulu June 2003

7. Ryan M (2003) Ask the Teacher: A Practitioner's Guide to Teaching and Learning in the Diverse Classroom Allyn and Bacon Boston

8. Kirk J \& Orr R (2003) A primer on the effective use of threaded discussion forums (ERIC Document Reproduction Service No. ED472738)

9. Serdyukov P and Hill R. (2003) Virtual Challenges and Real Solutions. In: Proceedings of E-Learn 2003 World Conference on E-Learning in Corporate, Government, Healthcare, \& Higher Education Phoenix November 7-11, 2003.

10. Prestera G \& Moller L (2001). Facilitating asynchronous distance learning: Exploiting opportunities for knowledge building in asynchronous distance learning environments In: Proceedings of the Annual Mid-South Instructional Technology Conference Murfreesburo TN

11. Rogers, J (1989) Adults Learning Edition Open University Press Philadelphia PA

12. Brookfield S (1985) The Continuing Educator and Self-Directed Learning in the Community. In: New Directions for Continuing Education 25 (Self-Directed Learning: From Theory to Practice) S. Brookfield (ed) Jossey-Bass San Francisco

13. Elias J, and Merriam S (1980) Philosophical Foundations of Adult Education. Krieger Malabar, FL

14. Slavin R, Madden N, Dolan L, Wasik B, Ross S, Smith L., \& Dianda M. (1996) Success for A11: A summary of research. In: Journal of Education for Students Placed at Risk 1(1), 41-76. 